\title{
Motor's Braking Force of Electric Vehicle with Double Motors
}

\author{
Zhang Yan,Zhang Lanchuan,Jiang Kejun,Ji wenyu
}

(School of automobile and traffic engineering,Jiangsu University of Technology,ChangZhou)

Keywords: electric vehicle;double motors;motor braking;braking stability

Abstract: As the electric vehicle with different kinds of motors set at front wheel and rear wheel for example,the modified characteristics of motor's braking torque come out according to normal characteristics of motor's torque. Based on the motor's modified braking torque curve,the ralationship between braking force of motors set at front wheel or rear wheel and the vehicle speed were analyzed.Accroding to the ralationship of motors' braking force between front motor and rear motor,also the Curve I,Curve ECE,Curve $f$ and Curve $r$ with all kind of road adhesion coefficient, the braking stability was analyzed.The result showed that:the motor braking force could retain maximum when electric vehicle running at daily-used speed, then the wheel did not be locked when electric vehicle braking on the roads without ice or snow.

\section{Introduction}

Electric vehicle was the representative example of the low carbon emission, especially the electric vehicle with zero emission was recommended by governments and experts. Electric vehicle was driven by the electric motor. When the vehicle decelerating, electric motor was used as a generator for braking energy recovery and the braking force producing. At home and abroad, braking energy recovery of the electric vehicle, also the relationship between motor braking force and hydraulic brake force have been researched.Most cars were driven by front wheel.Braking force required by front wheel was larger than rear wheel.In order to recycle more energy,most electric vehicles had the motor set on front wheel.As the front-set motor for example,ralationship between motor braking force and normal hydraulic braking force,also the relationship between front-wheel's braking force and rear-wheel's braking force were analyzed based on the standard of energy recovery ratio.On the other hand,recently the wheel hub motor come out,more and more wheel hub motors were installed on electric vehicles, which had higher energy recovery ratio.However,the electric vehicle with wheel hub motors had equal front-wheel's braking force and rear-wheel's braking force when motor braking. Curve I was the vehicle's ideal front and rear wheel braking force curve when braking. The motor's braking distribution curve between front wheel and rear wheel deviated from Curve I seriously when vehicle was driven on roads with adhesion coefficient higher than the synchronous adhesion coefficient. The case would lead to low braking efficiency and no full use of road adhesion coefficient. So it was necessary to set different kind of motors on front and rear wheel,which improved the energy recovery ratio and made the distribution of braking force between front motor and rear motor more suitable.Study on the braking force distribution between front motor and rear motor was significant for selection of motors separately set on front wheel and rear whee ${ }^{[1-3]}$.

\section{Torque output characteristics of motor}

The torque output characteristics of motor were the key parameters for electric motor braking. When electric vehicle braking, the motor worked as a generator, the braking force provided 
by motor was related to motor's torque from energy recovery.More torque and more motor's braking force. The ideal torque output characteristics of motor were shown in formula 1 as follow ${ }^{[4]}$ :

$$
\mathrm{T}= \begin{cases}\frac{9549 \mathbb{P}_{\mathrm{n}}}{\mathrm{n}_{\mathrm{n}}}, & n<\mathrm{n}_{\mathrm{n}} \\ \frac{9549 \mathrm{P}_{\mathrm{n}}}{\mathrm{n}}, & \mathrm{n} \geq \mathrm{n}_{\mathrm{n}}\end{cases}
$$

In formula $1, \mathrm{~T}$ was torque, $\mathrm{P}_{\mathrm{n}}$ was motor's rated power, $\mathrm{n}_{\mathrm{n}}$ was motor's rated speed, $\mathrm{n}$ was motor's actual speed. When actual speed was larger than the rated speed,actual speed was inversely related to torque and motor's braking force. When actual speed was lower than the rated speed,the torque and motor's braking force were a fixed value.

\section{Characteristics of motor's braking force}

Although motor's torque was get by formula 1,braking progress was different from driving. When vehicle started to move,motor's torque would reach the maximum, so was the driving

force caused by motor. When vehicle speed was down to a certain value $n_{r}$ in the process of braking,the wheel's speed didn't provide enough energy to produce max braking force.At this time the motor's braking force would decrease rapidly to zero with wheel speed decreased.So the motor's braking force need to be modified according to formulal when wheel speed was low. If the battery didn't have constraint on the motor braking,the characteristics of motor's braking torque were shown in formula 2 as follow:

$$
\mathrm{T}_{\mathrm{r}}=\left\{\begin{array}{c}
9549 \mathrm{P}_{\mathrm{n}}-\operatorname{con} \frac{2}{2}, 0<\mathrm{n}<\mathrm{n}_{\mathrm{r}} \\
\frac{9549 \mathrm{p}_{\mathrm{n}}}{\mathrm{n}_{\mathrm{n}}}, \mathrm{n}_{\mathrm{r}}<\mathrm{n}<\mathrm{n}_{\mathrm{n}} \\
\frac{9549 \mathrm{P}_{\mathrm{n}}}{\mathrm{n}}, \mathrm{n} \geq \mathrm{n}_{\mathrm{n}}
\end{array}\right.
$$

In the formula 2, a was the correctional coefficient.The motor's braking force was shown in formula 3 as follow:

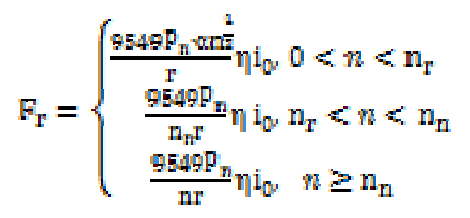

In the formula $3, \mathrm{r}$ was the wheel's radius, $\eta$ was efficiency of transmission system, $\mathfrak{i}_{0}$ was transmission ratio of ratarder.

\section{The stability conditions of the motor braking}

When front and rear wheel were locked in the process of braking,vehicle would lose steering ability, which were a serious threat to the safety of driving. So it was necessary to avoid the case when braking force distribution between front and rear wheel. The braking force distribition curve were close to Curve I as far as possible.Then the braking efficiency and utilization rate of road adhesion coefficient rose.

In order to ensure the steering stability and the enough braking efficiency,United Nations Economic Commission for Europe made a standard named ECE R13, which was a law about braking force of vehicle with double axles,National Standard of China also provided a similar 
requirement.All kind of vehicle drove on the road with adhesion coefficient $\phi$ between 0.2 and 0.8 , the braking strength $\mathrm{z} \geq 0.1+0.85(\phi-0.2)$. When vehicle was in all kind of loads, its front axle's utilization adhesion coefficient curve should be above its rear axle's utilization adhesion coefficient curve. According to the ECE standard,the relationship between front and rear wheel's braking force was shown as follow ${ }^{[5,6]}$ :

$$
\left\{\begin{array}{c}
F_{f}=\frac{z+0.07 G\left(b+z h_{g}\right)}{0.83 L} \\
F_{F}=G z-F_{f}
\end{array}\right.
$$

In formula $4, F_{f}$ was the front wheel's braking force, $F_{F}$ was the rear wheel's braking force. As $\mathrm{L}$ was the wheelbase of the vehicle, $\mathrm{b}$ was the distance between the rear wheel's center and centroid, $\mathrm{h}_{\mathrm{g}}$ was height of the centroid. $\mathrm{G}$ was the weight of the vehicle.

\section{Motor's braking force distribution of electric vehicle}

A electric vehicle was chosen for example,motor's braking force distribution was analyzed.There were double driving motors in the electric vehicle.Rated power of the motor set on front wheel was $60 \mathrm{kw}$, rated power of the motor set on rear wheel was $30 \mathrm{kw}$. The characteristics of two motors' torque were shown in the Figure 1.The braking torque of front motor rose with increased motor speed when motor speed was in the range of $0-800 \mathrm{r} / \mathrm{min}$. The braking torque keep on maximum that was $191 \mathrm{~N} \cdot \mathrm{m}$ when motor speed was in the range of $800-3000 \mathrm{r} / \mathrm{min}$. The braking torque decreased with increased motor speed when motor speed was in the range of $3000-5200 \mathrm{r} / \mathrm{min}$. The max motor speed was 5200r/min, at the same time the motor torque was $110 \mathrm{~N} \cdot \mathrm{m}$. The braking torque of rear motor rose with increased motor speed when motor speed was in the range of $0-560 \mathrm{r} / \mathrm{min}$. The braking torque keep on maximum that was $167 \mathrm{~N} \cdot \mathrm{m}$ when motor speed was in the range of 560-2000 $\mathrm{r} / \mathrm{min}$. The braking torque decreased with increased motor speed when motor speed was in the range of $2000-4700 \mathrm{r} / \mathrm{min}$. The max motor speed was $4700 \mathrm{r} / \mathrm{min}$, at the same time the motor torque was $71 \mathrm{~N} \cdot \mathrm{m}$.

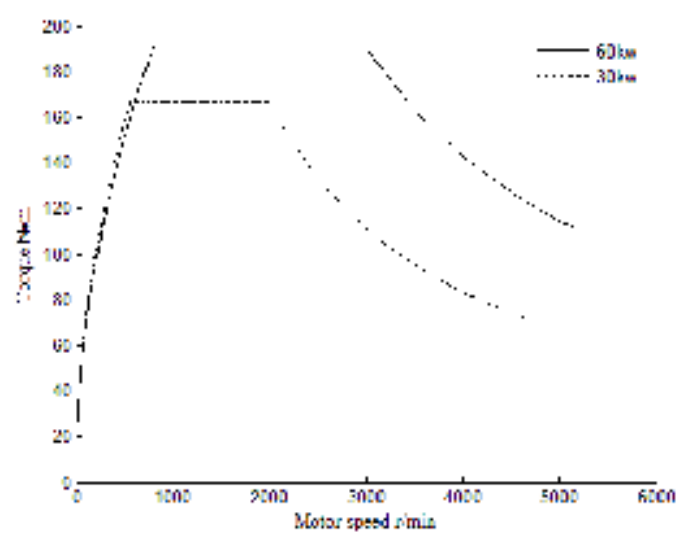

Fig.1 Braking torque of motors set on front and rear wheel

Each motor of the electric vehicle was connected with a reducer,the transmission ratio of each reducer was 2.As was shown in Figure 2, the relationship between motor's speed and vehicle's speed come out according to wheel's radius which was linear relationship. The max vehicle speed was $243 \mathrm{~km} / \mathrm{h}$ when driving, at the same time the motor speed was $4700 \mathrm{r} / \mathrm{min}$. The max braking torque of electric vehicle was $358 \mathrm{~N} \cdot \mathrm{m}$ when motor speed was in the range of $800-2000 \mathrm{r} / \mathrm{min}$, which was 
corresponding to vehicle speed from $41 \mathrm{~km} / \mathrm{h}$ to $103 \mathrm{~km} / \mathrm{h}$. This speed range was the commonly used speed range, which was full use of motor's maximum braking efficiency and could improve recovery of braking energy.

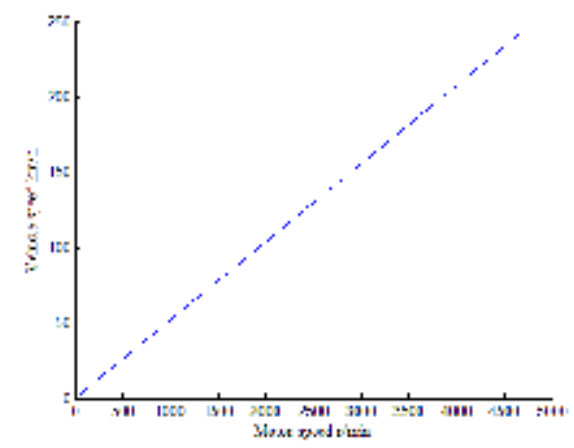

Fig.2 Relationship between motor's speed and vehicle's speed

As the max motor speed of rear motor was 4700r/min,the relationship about motor's braking force distribution between front motor and rear motor was analyzed in the motor speed rang of $0-4700 \mathrm{r} / \mathrm{min}$. The braking force of front motor and rear motor come out according to each motor's torque and wheel radius. The distribution curve $\beta_{0}$ between front motor's braking force and rear motor's braking force was shown in Figure 3, which was a multi-segment line. The first section line of Curve $\beta_{0}$ from left side indicated that braking force of front motor and rear motor rose with increased motor speed when motor speed was in the range of $0-560 \mathrm{r} / \mathrm{min}$. The second section line of Curve $\beta_{a}$ from left side indicated that front motor's braking force rose with increased motor speed,however rear motor's braking force remained unchanged which was $1214 \mathrm{~N}$ when motor speed was in the range of $560-800 \mathrm{r} / \mathrm{min}$. The inflection point in the right-hand corner of Curve $\beta_{0}$ indicated that the braking force of front motor and rear motor remained unchanged when motor speed was in the range of $800-2000 \mathrm{r} / \mathrm{min}$. The front motor's braking force was $1389 \mathrm{~N}$ and rear motor's braking force was $1214 \mathrm{~N}$. The third vertical line of Curve $\beta_{0}$ from left side indicated that front motor's braking force remained unchanged which was $1389 \mathrm{~N}$, however rear motor's braking force decreased with increased motor speed when motor speed was in the range of 2000-3000r/min. The fourth section line of Curve $\beta_{0}$ from left side indicated that front motor's and rear motor's braking force decreased with increased motor speed when motor speed was in the range of 3000-4700 r $/ \mathrm{min}$. When motor speed was in the range of 560-3000r/min, the vehicle speed was in the range of $29-155 \mathrm{~km} / \mathrm{h}$ which was common driving speed.In this speed range,sum of front motor's braking force and rear motor's braking force was larger than other speed. When vehicle's speed was under $29 \mathrm{~km} / \mathrm{h}$, the common hydraulic braking system would play a better role than motor braking. 


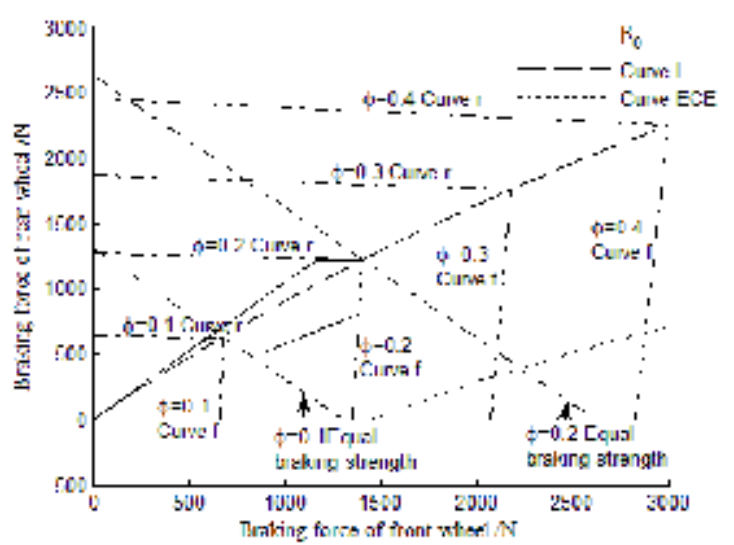

Fig.3 The relationship of braking force between the motor set on front wheel and the motor set on rear wheel

\section{Stability of motor braking in electric vehicle}

Curve I and Curve ECE were shown in the Figure 3,also the curve of equal braking strength,curve $f$ and curve $r$. The relative position between Curve $\beta_{0}$ and several curves before show that:(1)All part of Curve $\beta_{0}$ was above Curve ECE, which met the requirement of ECE rules about braking distribution between front wheel and rear wheel.(2) The point of intersection between Curve $\beta_{o}$ and Curve I was shown in Figure 3. Corresponding to the point,front motor's braking force was $1389 \mathrm{~N}$ and rear motor's braking force was $1208 \mathrm{~N}$, the motor speed was $2011 \mathrm{r} / \mathrm{min}$ and the synchronous adhesion coefficient $\Phi_{\Omega}$ was 0.197 .(3)When motor speed $\mathrm{n}$ was on the condition that $0<\mathrm{n}<2011 \mathrm{r} / \mathrm{min}$, Curve $\beta_{0}$ was above Curve I, so the rear wheel could be locked ahead of front wheel when vehicle driven on the road whose adhesion coefficient $\phi$ was on the condition that $0<\phi<0.197$.(4)When motor speed $n$ was on the condition that $n>2011 \mathrm{r} / \mathrm{min}$, Curve $\beta_{0}$ was under Curve I,so the front wheel could be locked ahead of rear wheel when vehicle driven on the road whose adhesion coefficient $\phi$ was on the condition that $0<\phi<0.197$.(5)When motor speed $n$ was $2011 \mathrm{r} / \mathrm{min}$, the front wheel and rear wheel would be locked at the same time when vehicle driven on the road whose adhesion coefficient $\phi$ was 0.197 .

According to existing research, the adhesion coefficient of dry cement or asphalt pavement was between 0.7 and 1 . The adhesion coefficient of wet cement or asphalt pavement was between 0.4 and 0.6. The adhesion coefficient of just rainy road surface was between 0.3 and 0.4.The adhesion coefficient of road covered by ice or snow was between 0.1 and 0.2.If electric vehicle driven on condition of daily weather and common road,Curve $\beta_{\sigma}$ didn't intersect with Curve $f$ or Curve r.So front wheel or rear wheel would not be locked when motor braking. When motor braking on the road covered by ice or snow, vehicle speed was slow in general and ABS would work when 
some wheel locked.At the same time,the motor braking would be cut off,so the safety of electric vehicle could be ensured, the braking energy recovery was paused.

\section{Summary}

(1)When electric vehicle driven on the speed between $41 \mathrm{~km} / \mathrm{h}$ and $103 \mathrm{~km} / \mathrm{h}$, the total motor braking torque reached maximum of $358 \mathrm{~N} \cdot \mathrm{m}$, which made full use of motor's maximum braking performance and improved safety,ratio of braking energy recovery.

(2) All part of Curve $\beta_{0}$ was above Curve ECE, which met the requirement of ECE rules about braking distribution between front wheel and rear wheel.

(3) Front wheel or rear wheel would not be locked when motor braking on the road except that covered by ice or snow, the safety and braking stability were improved.

(4)When vehicle braking on the road covered by ice or snow,ABS worked and motor braking would be cut off,safety of vehicle could be ensured.

\section{Acknowledgement}

We acknowledged the projects' support of University's Natural Science Program of Jiangsu Province(Contract No.14KJD580003 and 13KJB580004), Fundamental and Applied Research Program of Jiangsu University of Technology(Contract No. KYY13019 and KYY13020 ), National Natural Science Fund of China(Contract No.51305175).

\section{References}

[1]Gong Xianwu,Zhang Lijun,Ma Jian and so on.Braking force distribution of electric vehicles based on braking stability.Journal of Chang'an University(Natural Science Edition),2014,pp.103-108.

[2]Guo Jingang, Wang Junping,Cao Binggang.Optimization based braking force distribution for electric vehicles.Mechanical Science and Technology for Aerospace Engineering,2011,pp.1485-1499.

[3]Zhang Jihong.Research of electric vehicle regenerative braking control strategy based on EHB system. Master's Degree Thesis of Jilin University(2011).

[4]Li Guofei,Lin Yi,He Hongwen.Regenerative braking control strategy for electric vehicle.Transactions of Beijing Institute of Technology,2009,pp.520-524.

[5]Zhang Yan,Liu Chengye,He Ren and so on.Influence of eddy current retarder on vehicle braking force utilization.Journal of Traffic and Transportation Engineering,2011, pp.62-67.

[6]Yu Zhisheng. Theory of Automobile.Beijing:China Machine Press(2010). 